\title{
Análisis Morfométrico del Número de Odontoblastos en Recubrimientos Directos con Hidróxido de Calcio y Propóleos en Canes
}

\author{
Morphometric Analysis of Odontoblasts Number in Direct Capping \\ with Calcium Hydroxide and Propolis in Dogs
}

"Andrés Roig; ${ }^{* *}$ Jorge Henríquez; ${ }^{* * *}$ Marysol Alvear $\&{ }^{* * * * *}$ Luis A. Salazar

ROIG, A.; HENRÍQUEZ, J.; ALVEAR, M. \& SALAZAR, L.A. Análisis morfométrico del número de odontoblastos en recubrimientos directos con hidróxido de calcio y propóleos en canes. Int. J. Morphol., 29(3):799-805, 2011.

RESUMEN: El propóleos se ha utilizado en medicina desde épocas antiguas, una de sus indicaciones en medicina oral y odontológica es como material de recubrimiento directo. Así, el objetivo de este estudio fue cuantificar la neoformación odontoblástica en piezas dentarias de canes en recubrimientos directos. Se realizaron perforaciones en un total de 12 piezas dentarias, la mitad de las cuales fueron recubiertas con propóleos y la otra mitad con hidróxido de calcio. En todos los casos se obturaron las piezas dentarias con cemento de vidrio-ionómero. Al cabo de dos semanas, se realizaron las extracciones de las piezas dentarias, fijándolas en formalina tamponada; se efectuaron cortes histológicos de las piezas, los cuales se tiñeron con hematoxilina-eosina, con el fin de poder realizar la cuantificación de los núcleos odontoblásticos presentes tanto en las zonas alejadas de la perforación, como en las zonas cercanas a las lesiones. Se observó una similar actividad odontoblástica en las zonas cercanas a las lesiones al utilizar cualquiera de los dos materiales ( $\mathrm{p}=0,9325)$, diferenciándose solamente en la disposición de las células neoformadas, que en el caso de utilizar propóleos fueron en empalizada, semejante a las zonas sanas, en cambio, al utilizar hidróxido de calcio no se observó dicho ordenamiento.

PALABRAS CLAVE: Propóleos; Neoformación odontoblástica; Recubrimiento Directo; Hidróxido de Calcio.

\section{INTRODUCCIÓN}

El complejo dentino-pulpar es la verdadera unidad funcional y protectora del diente (Cabrera, 2008); en variadas situaciones clínicas odontológicas, puede ocurrir una exposición pulpar accidental y en estos casos, el hidróxido de calcio $(\mathrm{Ca}(\mathrm{OH}) 2)$ es el medicamento de elección para cubrir la zona de pulpa expuesta (Niinuma, 1999).

El recubrimiento pulpar es un procedimiento o técnica en la que se coloca un medicamento y/o material dental sobre la pulpa expuesta aislándola del exterior, para no sólo impedir la inflamación y la posible necrosis de ésta, sino que también facilitar su curación y la mantención de sus funciones (Cabrera). Es importante, contar con materiales que posean características antibacterianas y biocompatibles (Wang \& Hume, 1988).
Baume \& Holz (1981) restringen el empleo del recubrimiento pulpar directo a los casos en los que la pulpa no está inflamada y el sellado es verdaderamente hermético. Seltzer \& Bender (1987) reconocen que no es muy recomendable el recubrimiento pulpar directo en exposiciones cariosas.

La neoformación dentinaria es dependiente de la actividad odontoblástica (Montenegro et al., 1997). Pourtois (1966) sugiere que el ectomesénquima pulpar posee cierta capacidad de autodiferenciación en tejido odontogénico. En una pulpa joven los odontoblastos toman la forma de empalizada, cual epitelio pseudoestratificado. El odontoblasto se considera una "célula posmitótica fija", y, deben ser reemplazados por células subyacentes que maduran a partir de

\footnotetext{
Programa de Magíster en Ciencias, mención Morfología, Universidad de La Frontera, Temuco, Chile.

** Anatomía Normal. Depto. de Ciencias Básicas. Facultad de Medicina. Universidad de La Frontera, Temuco, Chile.

**** Departamento de Ciencias Químicas y Recursos Naturales Facultad de Medicina. Universidad de La Frontera, Temuco, Chile.

**** Centro de Biología Molecular y Farmacogenética, Departamento de Ciencias Básicas y Núcleo de Desarrollo Científico - Tecnológico en Biorecursos, (BIOREN-UFRO), Facultad de Medicina, Universidad de La Frontera, Temuco, Chile.

Este estudio fue financiado parcialmente mediante proyecto FONDEF de CONICYT (D05I10021).
} 
precursores indiferenciados en división, o mediante rediferenciación de los fibroblastos (Ingle \& Bakland, 2004), se requiere un tiempo para la proliferación y la diferenciación de nuevos odontoblastos de reemplazo (Stanley et al., 1966). Yamamura et al. (1980) hallaron que los fibroblastos pulpares parecen sufrir desdiferenciación para volver a ser células mesenquimáticas indiferenciadas. Yamamura (1985) concluye que los odontoblastos desplazados de los túbulos pueden ser sustituidos por células que migran desde la zona rica en células de la pulpa (Cohen \& Burns, 1994).

El hidróxido de calcio es un polvo altamente alcalino, poco soluble en agua. Al aplicarlo al tejido pulpar provoca la necrosis por coagulación del tejido subyacente, lo que estimula a las células pulpares sanas adyacentes. Los agentes adhesivos (agentes bonding) y composites también han sido estudiados como material de recubrimiento, probando su éxito (Scarano et al., 2003). Se han obtenido buenos resultados al utilizar el agregado trióxido mineral (MTA) (Cabrera). Sabir et al. (2005) investigaron los propóleos, Cabrera la Uncaria tormentosa (uña de gato) y la Calendula officinalis Linné Europea (Maravilla).

En cuanto al propóleos, Bretz et al. (1998) no encuentran diferencias en el potencial antimicrobiano y de cicatrización, en pulpas expuestas en comparación al hidróxido de calcio. Toloza \& Cañizares (2002) describen los componentes de los extractos de propóleos: lactonas, saponinas, fenoles, triterpenos, esteroides, taninos, flavonoides, alcaloides y en menor grado grupos aminos, aunque en el caso de los extractos acuosos, detectaron la presencia de leucoantocianidinas.

Los estudios histológicos demuestran que la pasta dental a base de propóleos al igual que la de hidróxido de calcio inhiben el crecimiento bacteriano y estimulan la reparación de la dentina (Farré et al., 2004). Martin \& Pileggi (2004) demostraron la utilidad del propóleos en el almacenamiento y transporte de dientes avulsionados, Sabir et al. sugieren que los flavonoides del propóleos pueden estimular la dentinogénesis reparativa.

Peña (2008) indica que los propóleos disponibles en Chile, contienen en mayor porcentaje terpenos y flavonoides (principalmente pinocembrina). La fase flavonoide otorga las características antiinflamatorias. Sánchez-Ayala et al. (2008) adicionan propóleos al hidróxido de calcio, lo que disminuyó el potencial antibacteriano. Cabrera indica que los propóleos, al igual que la Calendula officinalis Linné, contienen principalmente flavonoides.

El presente estudio evalúa la respuesta odontoblástica (actividad odontoblástica) comparando el porcentaje de neoformación odontoblástica frente al propóleos, en compa- ración al hidróxido de calcio al ser utilizados como medicamentos de recubrimientos pulpares directos en piezas dentarias de canes, mediante histomorfometría de neoformación odontoblástica.

\section{MATERIAL Y MÉTODO}

Animales. El estudio se realizó en 2 animales de experimentación (Canis lupus familiaris). Los canes reunían las siguientes condiciones: adultos, sin patologías sistémicas, dentarias, oclusales ni articulares y no estaban ingiriendo ningún tipo de medicamento. Los animales de experimentación se sedaron con midazolam; se les administró acepromazina maleato $1 \%$ y tiopental sódico, se desinfectó la cavidad oral mediante clorhexidina, se anestesió infiltrativamente con lidocaína con adrenalina 1.1000.000. Se aisló en forma absoluta la pieza dentaria a trabajar, se desinfectó la zona aislada mediante tórula de algodón embebida con solución de clorhexidina sin alcohol. Se realizó una cavidad con fresa nueva y estéril de diamante redonda $\mathrm{N}^{\circ} 10$ de talle largo con abundante refrigeración hasta realizar exposición pulpar sin penetrar al interior de la cámara pulpar (Fig. 1). Posterior a la perforación se irrigó con suero fisiológico por 20 segundos y posteriormente se colocó una microtórula de algodón estéril embebida con suero fisiológico en la cavidad operatoria durante 1 minuto. Se secó colocando una mota de algodónestéril seco, por 2 minutos en la cavidad operatoria. Se sorteó el material a colocar como recubrimiento: hidróxido de calcio en cápsulas, mezclado con agua destilada, ó propóleos en cápsulas blandas (Laboratorios Arama®).

Se colocó el material de recubrimiento delicadamente. Se obturó con vidrio ionómero. Se realizó el mismo procedimiento en la pieza dentaria contralateral, utilizando el otro material. En cada animal de experimentación se trabajó en las siguientes 6 piezas dentarias: $3^{\circ}$ incisivos superiores y caninos superiores e inferiores. Se retiró la aislación, se desinfectó la cavidad oral con spray de clorhexidina. Se les administró ketorolaco $0,3 \mathrm{mg}$ sublingual cada $12 \mathrm{hrs}$ por tres días. A los 14 días y luego de comprobar vitalidad pulpar, se realizó extracción de las piezas dentarias bajo anestesia general. Las piezas dentarias una vez extraídas, fueron lavadas en suero fisiológico e inmediatamente fijadas en una solución de formalina tamponada (al 10\%). Se montaron en portaobjetos 5 cortes longitudinales en cada pieza dentaria que coincidieron con la perforación pulpar. Se tincionaron con técnica hematoxilina-eosina, y se observaron en microscopio óptico de transmisión de luz. La morfometría del porcentaje de actividad odontoblástica se realizó utilizando fotografías obtenidas al microscopio de luz y cámara conectados a PC, con una magnificación de 100x, en que se midieron 6 campos inme- 

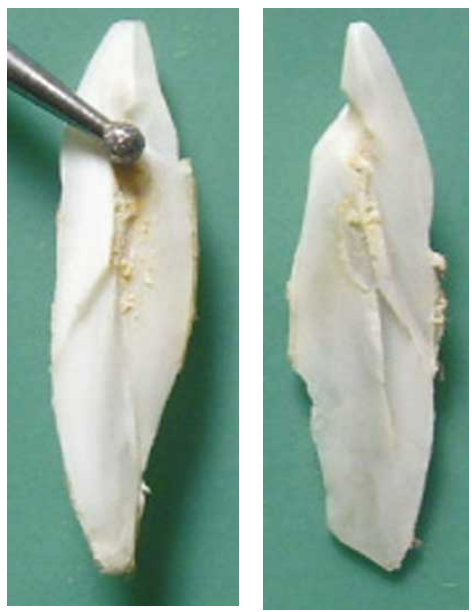

Fig. 1. Ángulo de la cavidad realizada (siempre se realizó acceso por vestibular).
B a los 70 minutos. Los compuestos se detectaron a una longitud de onda de $290 \mathrm{~nm}$, con una sensibilidad de 0,001; el volumen de inyección fue $10 \mu \mathrm{L}$. La identificación de los compuestos fenólicos se realizó mediante el uso de los estándares miricetina, kaempferol, quercetina, ácido cafeico, galangina, pinocembrina, apigenina, ácido cafeico fenil éster (CAPE) y resveratrol (Sigma, EE.UU.)

Análisis estadístico. Las significancias de las diferencias observadas fueron analizadas mediante análisis estadístico (promedio, valor máximo, valor mínimo, mediana, desviación estándar, test $\mathrm{t}$ de Student). Se utilizó en el análisis estadístico el software Graph Pad PRISM versión 4. Se consideró para el análisis estadístico un $95 \%$ de intervalo de confianza, con un valor de $\mathrm{p}<0,05$. pantalla de televisión de 29 pulgadas, donde cada cuadrícula correspondiese a $100 \mu \mathrm{m}$ de lado. Se midieron también el número de odontoblastos en 6 zonas alejadas de la perforación operatoria. Se estudiaron 864 campos.

Análisis cromatográfico. Se preparó un extracto etanólico de propóleos, el que se diluyó 1:4 en agua destilada y, posteriormente, se filtró en papel Wathman $\mathrm{N}^{\circ} 2$ para descartar las ceras. A continuación, se le aplicó un nuevo proceso de filtrado con filtro de acetato de celulosa de $0,2 \mathrm{~mm}$ a fin de esterilizar la solución. El análisis se efectuó en un Cromatógrafo Líquido de Alta Precisión (HPLC) MerckHitachi, equipado con una bomba modelo L-6200, un detector UV-visible, modelo L-4200 y un horno para columna Phenomenex Terma Sphere, modelo TS-130. La separación se realizó en una columna RP-18 (12,5 x 0,4 cm, tamaño de partícula $5 \mu \mathrm{m}$ ) (Merck, Alemania), la cual se eluyó a $25^{\circ} \mathrm{C}$ utilizando como fase móvil la mezcla de ácido fórmico $5 \%$ en agua (A) y Metanol (B). La separación de los compuestos se realizó mediante una corrida isocrática de 0 a 10 minutos, con la mezcla A $70 \%$ y B 30\%, seguida de un gradiente hasta $100 \%$

\section{RESULTADOS Y DISCUSION}

El análisis cromatográfico del propóleos estudiado indica que éste presenta los siguientes compuestos polifenólicos: ácido cafeico, miricetina, quercetina, kaempferol, apigenina, pinocembrina, galangina y CAPE (Fig. 2). Resultados similares fueron encontrados previamente por Peña y Herrera $e t$ al. (2010) al analizar propóleos chilenos.

El análisis morfométrico indica que hay diferencias estadísticamente significativas entre las zonas cercanas y las lejanas a la lesión (zonas sanas). Lo que indica que los campos seleccionados para nuestro estudio fueron los adecuados (Tabla I). Al comparar el número de odontoblastos en las zonas cercanas a la perforación en los dientes tratados con propóleos y en los tratados con hidróxido de calcio, se observa que no existen diferencias estadísticamente significativas en la actividad odontoblástica en recubrimientos directos con uno u otro producto (Tabla II).

El número máximo de células en las zonas de per-

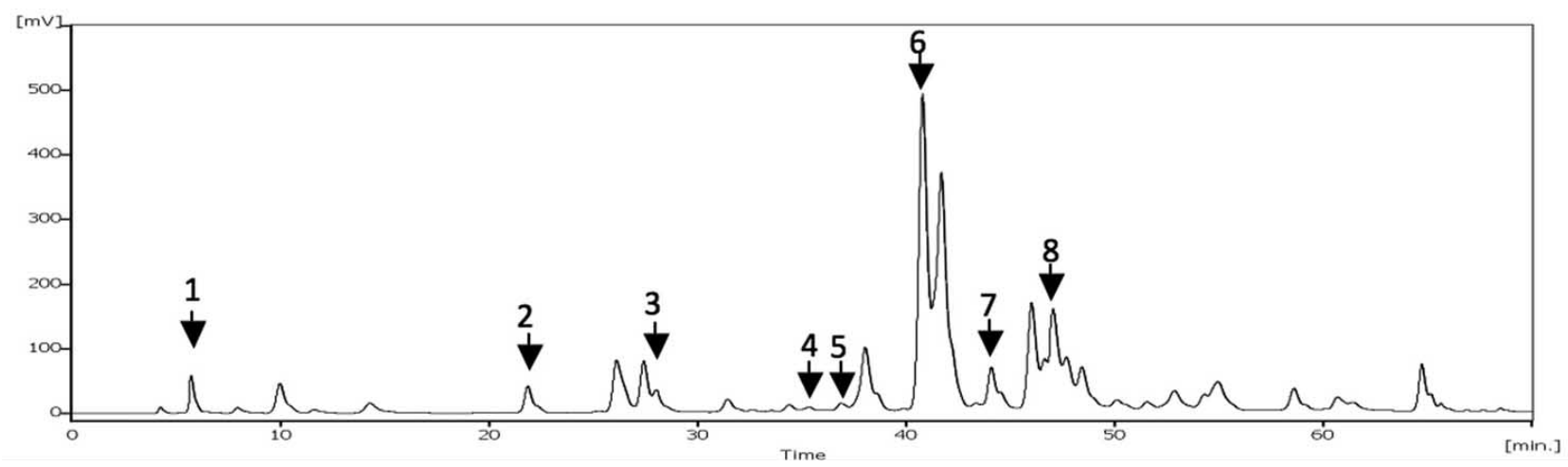

Fig. 2. Cromatograma de extracto de propóleos comercial chileno. Longitud de onda: $290 \mathrm{~nm}$, volumen de inyección: $10 \mu \mathrm{L}$. Compuestos identificados: 1 , ácido cafeico; 2, miricetina; 3, quercetina 4, kaempferol; 5, apigenina; 6, pinocembrina; 7, galangina; 8, ácido cafeico fenil éster (CAPE). 
Tabla I. Número de odontoblastos en zonas de perforación y zonas sanas.

\begin{tabular}{lcc}
\hline & Zona Perforación & Zona Sana \\
\hline Prome dio & $4,01^{*}$ & $7,81^{*}$ \\
Mediana & 3 & 8 \\
D.S. & 2,27 & 2,78 \\
Mínimo & 0 & 0 \\
Máximo & 16 & 15 \\
\hline
\end{tabular}

*p $<0,0001$ (Test t de Student).

Tabla II. Número de odontoblastos en zonas de perforación en dientes con recubrimiento directo con propóleos y con hidróxido de calcio.

\begin{tabular}{lcc}
\hline Pecubrimiento & $\begin{array}{c}\text { Recubrimiento con } \\
\text { con propóleos }\end{array}$ & $\begin{array}{c}\text { hidróxido de calcio } \\
\text { Prome dio }\end{array} 4^{*}, 00^{*}$ \\
Mediana & 4 & 4 \\
S. D. & 2,15 & 2,38 \\
Mínimo & 0 & 0 \\
Máximo & 13 & 16 \\
\hline
\end{tabular}

*p $=0,9325$ (Test t de Student). foración fue 13 en los caninos superiores (Baume \& Holz), y 6 en $\operatorname{los} 3^{\circ}$ incisivos superiores. El promedio de odontoblastos en las zonas de perforación fue levemente mayor en los caninos $(4,40)$ que en los $3^{\circ}$ incisivos superiores $(3,25)$ en los dientes tratados con hidróxido de calcio.

Los caninos inferiores cuyas perforaciones fueron recubiertas con hidróxido de calcio presentaron una mejor actividad odontoblástica en la zona de la lesión que los caninos superiores recubiertos con propóleos. Los caninos superiores cuyas perforaciones fueron recubiertas con propóleos presentaron una mejor actividad odontoblástica en la zona de la lesión que los caninos inferiores recubiertos con propóleos.

En cuanto a la histología, se observaron diferencias en la forma y disposición de los núcleos de los odontoblastos en las zonas cercanas a la perforación, según se haya utilizado como recubrimiento directo propóleos o hidróxido de calcio. En la mayoría de los cortes de las zonas de perforación en dientes tratados con hidróxido de calcio no se observa la característica disposición en empalizada observada en las zonas alejadas de la lesión. En la mayoría de los cortes de dientes en las zonas de perforación de dientes tratados con propóleos se observa una disposición de los núcleos de los odontoblastos
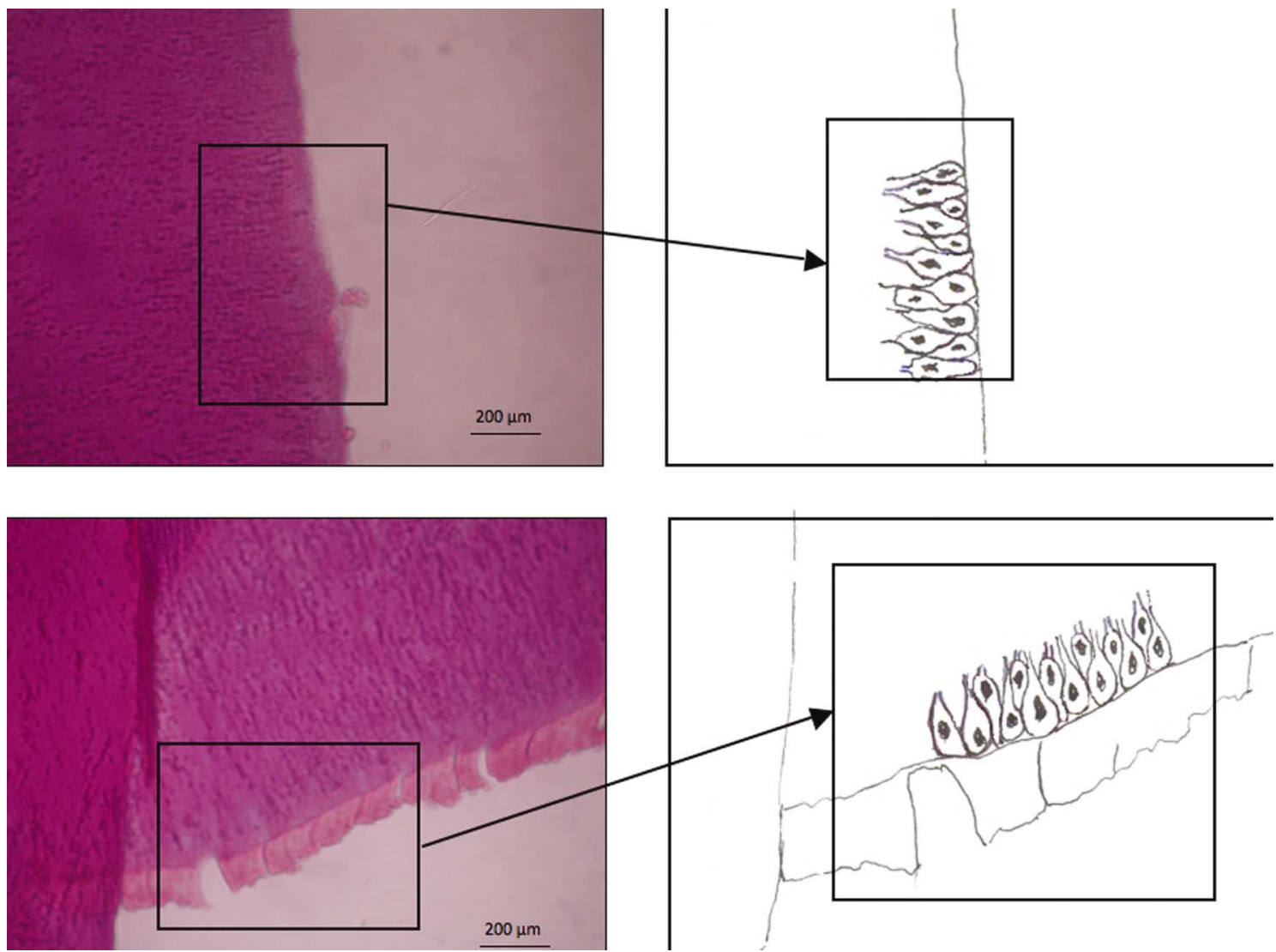

Fig. 3. Zonas sana (arriba) y zona perforación (abajo) en canino inferior de animal de experimentación n 2 tratado con propóleos. Se aprecia similitud en la disposición de los núcleos de los odontoblastos (en empalizada). 

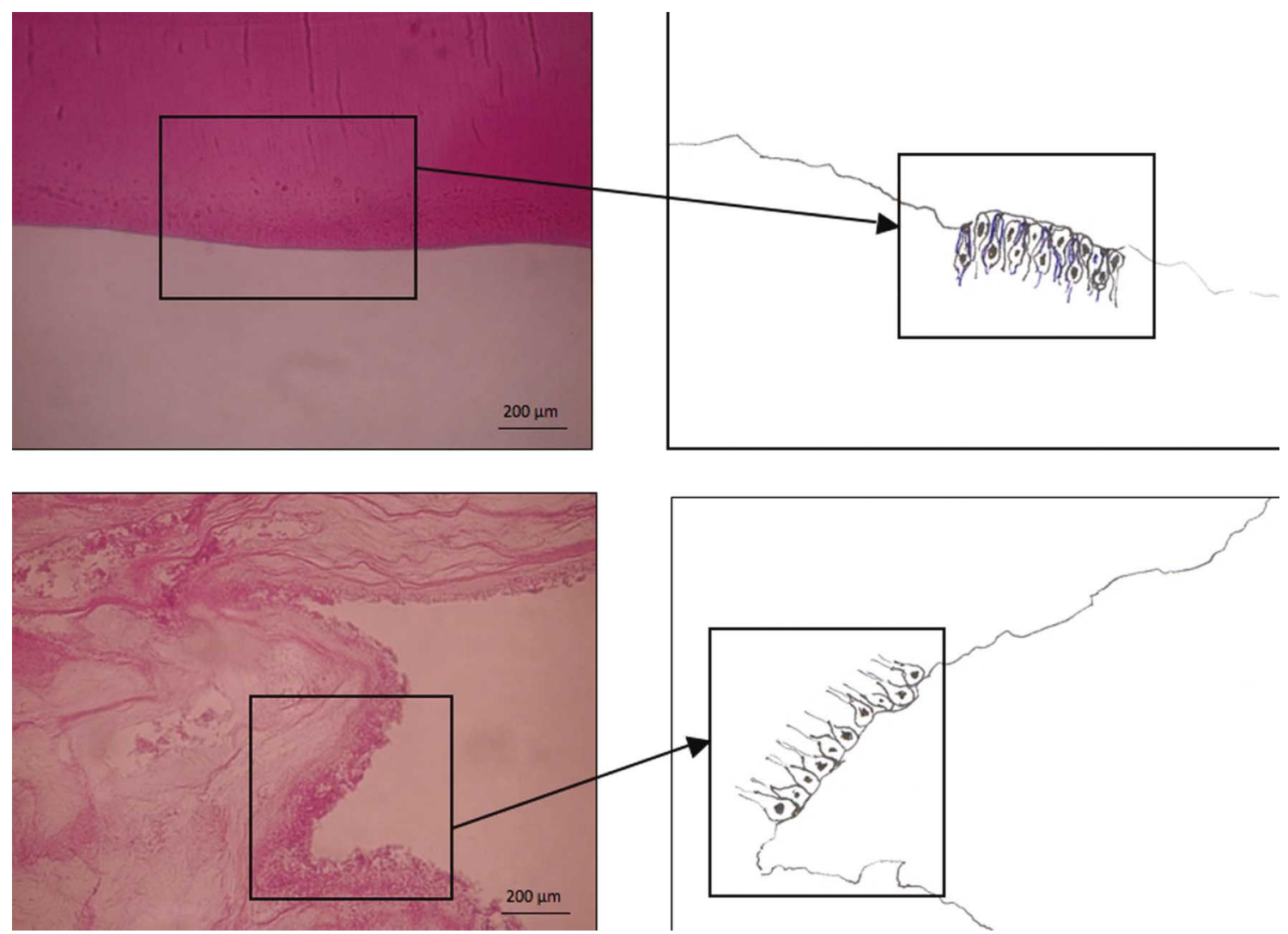

Fig. 4. Zona sana (arriba) y zona perforación (abajo) en pieza dentaria lateral superior de animal de experimentación n 1 tratado con hidróxido de calcio. Se aprecia distinta disposición de los núcleos de los odontoblastos (en la zona de perforación no hay disposición en empalizada).

con una disposición similar (en empalizada) a la observada en las zonas alejadas de la lesión. Lo anterior se muestra en las Figuras 3 y 4.

Las zonas de la perforaciones tratadas con hidróxido de calcio o con propóleos como recubrimiento directo, presentaron una actividad odontoblástica adecuada; resultado similar al obtenido por Cabrera al comparar hidróxido de calcio y Calendula officinalis Linn. Además, nuestros resultados coinciden a los descritos por Farré et al., en cuanto a que los propóleos estimulan la reparación de la dentina; y por Bretz et al., como regeneradores de la pulpa dentaria y como estimulantes de la formación de dentina reparativa.

La actividad odontoblástica fue similar al utilizar los dos productos, comprobado en el análisis estadístico, lo que evidencia la utilidad del propóleos como recubrimiento directo, en relación a determinar una actividad odontoblástica similar a la del hidróxido de calcio. En cuanto a la mejor respuesta en los caninos superiores al ser tratados con propóleos, se explica por las mejores características físicas del propóleos utilizado en cuanto a viscosidad, fluidez y adhesión, por lo que debió permanecer en contacto íntimo con la pulpa expuesta.
En cuanto a la disposición en empalizada: el hidróxido de calcio, al ser un material alcalino, puede ocasionar el estímulo de células no odontoblásticas, por lo que provoca que la disposición celular no sea en empalizada. Los propóleos vendrían, por tanto a ser un material más biológico, al crear una barrera formada por células dispuestas en forma similar a la pared original que fue dañada.

Se sugiere continuar las investigaciones en piezas dentarias de humanos y realizar un estudio inmunohistoquímico. No recomendamos fabricar un compuesto que incorpore tanto propóleos como hidróxido de calcio en un mismo material de recubrimiento directo, porque se alteraría el pH alcalino con el que actúa el hidróxido de calcio, o disminuiría su potencial antimicrobiano, tal como demuestra Sánchez-Ayala et al. Sí es de interés el poder aislar moléculas de los propóleos que participan en los procesos reparativos, de las que aportan solamente los aspectos de coloración, de modo de poder contar con un material que evite las tinciones de los tubulillos dentinarios, o por translucidez alteren el color de la obturación provisoria. También es útil investigar si los propóleos de color blanco o amarillo claro estimulan una actividad odontoblástica similar al propóleos estudiado. 


\section{AGRADECIMIENTOS}

Al Dr. Carlos Alberto Mandarim-de-Lacerda, Profesor Titular de la Universidade do Estado do Rio de Janeiro (RJ, Brasil), por haber realizado parte del procesamiento de las muestras histológicas.

ROIG, A.; HENRÍQUEZ, J.; ALVEAR, M. \& SALAZAR, L. A. Morphometric analysis of odontoblasts number in direct capping with calcium hydroxide and propolis in dogs. Int. J. Morphol., 29(3):799-805, 2011.

SUMMARY: Since ancient times, propolis has been used in medicine, while in oral medicine and dentistry it has been indicated as a direct capping material. The aim of this study was to quantify the odontoblast activity in drilling holes on dog's teeth (canine and incisor) during direct capping. Perforations were carried out in a total sample of 12 dental pieces. In half of the sample teeth were capped with propolis, and in the other half with calcium hydroxide. In all cases teeth were obturated with glass ionomer cement. Extraction of the teeth was realized after two weeks, and teeth were fixed in buffered formalin. Histological cuts of the pieces were made and stained with hematoxylin-eosin in order to carry out quantification of nuclei presence in healthy areas (away from the perforation, as well as in areas adjacent to injuries. Results showed similar odontoblast activity while using either of the materials, $(\mathrm{p}=0.9325)$, only differing in the arrangement of newly formed cells which in the cases where propolis was used, were palisading, similar to healthy areas. On the other hand, the same order was not observed when calcium hydroxide was used.

KEY WORDS: Propolis; Odontoblast neoformation; Direct capping; Calcium hydroxide.

\section{REFERENCIAS BIBLIOGRÁFICAS}

Baume, L. J. \& Holz, J. Long term clinical assessment of direct pulp capping. Int. Dent. J., 31(4):251-60, 1981.

Bretz, W. A.; Chiego, D. J. Jr.; Marcucci, M. C.; Cunnha, I.; Custódio, A. \& Schneider, L. G. Preliminary report on the effects of propolis on wound healing in the dental pulp. Z. Naturforsch. C., 53(11-12):1045-8, 1998.

Cabrera, M. A. Dentina terciaria o de reparación inducida por extracto de caléndula Officinalis linn. Europea en molares de ratas Norvegicus Albinus, Tesis Doctoral Facultad de Odontología Departamento de Estomatología, Universidad de Sevilla, 2008.

Cohen, S. \& Burns, R. Endodoncia. Los caminos de la Pulpa. $5^{\mathrm{a}}$ ed. México D. F., Médica Panamericana, 1994.

Farré, R.; Frasquet, I. \& Sánchez, A. El própopolis y la salud. Ars Pharm., 45(1):21-43, 2004.

Herrera, C.; Fritz, O.; Montenegro, G.; Alvear, M.; Del Sol, M. \& Salazar, L. A. El propóleos reduce la esteatosis hepática inducida por dieta en ratones. Int. J. Morphol., 28(1):75-84, 2010.

Ingle, J. I. \& Bakland, L. K. Endodoncia. $5^{\mathrm{a}}$ ed. Mexico D. F. McGraw-Hill Interamericana, 2004.
Martin, M. P. \& Pileggi, R. A. A quantitative analysis of Propolis: a promising new storage media following avulsion. Dent. Traumatol., 20(2):85-9, 2004.

Montenegro, M. A.; Mery, C. \& Aguirre, A. Histología y embriología del Sistema Estomatognático. Santiago, Facultad de Odontología Universidad de Chile, 1997.

Niinuma, A. Newly developed resinous direct pulp capping agent containing calcium hydroxide (MTYA-Ca). Int. Endod. J., 32(6):475-83, 1999.

Peña, R. Estandarización en propóleos: antecedentes químicos y biológicos. Cien. Inv. Agr. 35(1):17-26, 2008.

Pourtois, M. Study of the differentiation of odontoblasts in "in vitro" culture. Arch. Biol., 77(1):107-37, 1966.

Sabir, A.; Tabbu, C. R.; Agustiono, P. \& Sosroseno, W. Histological analysis of rat dental pulp tissue capped with propolis. J. Oral Sci., 47(3):135-8, 2005.

Sanchez-Ayala. A.; Silveira, C. M. M. \& Dos Santos, E. B. Addition of propolis to calcium hydroxide and its influence on antibacterial action. Cienc. Odontol. Bras., 11(3):81-6, 2008.

Scarano, A.; Manzon, L.; Di Giorgio, R.; Orsini, G., 
ROIG, A.; HENRÍQUEZ, J.; ALVEAR, M. \& SALAZAR, L. A. Análisis morfométrico del número de odontoblastos en recubrimientos directos con hidróxido de calcio y propóleos en canes. Int. J. Morphol., 29(3):799-805, 2011.

Tripodi, D. \& Piattelli, A. Direct capping with four different materials in humans: histological analysis of odontoblast activity. J. Endod., 29(11):729-34, 2003.

Seltzer, S. \& Bender, I. B. La Pulpa Dental. Consideraciones Biológicas en los Procedimientos Odontológicos. $3^{\circ}$ ed. Mexico D. F., El Manual Moderno, 1987. pp.265-84.

Stanley, H. R.; White, C. L. \& Mccray, L. The rate of tertiary (reparative) dentin formation in the human tooth. Oral Surg. Oral Med. Oral Pathol., 21(2):1809,1966

Toloza, L. \& Cañizares, E. The collection, characterization and evaluation of antimicrobial activity of propolis extracts from Campeche, Mexico. Ars Pharm., 43(12):187-204, 2002.

Wang, J. D. \& Hume, W. R. Diffusion of hydrogen ion and hydroxyl ion from various sources through dentine. Int. Endod. J., 21(1):17-26, 1988.

Yamamura, T.; Shimono, M.; Koike, H.; Terao, M.; Tanaka, Y.; Sakai, Y.; Inoue, T.; Yoshiki, S.; Tachikawa, T.; Kawahara, H. \& Watanabe, O. Differentiation and induction of undifferentiated mesenchymal cells in tooth and periodontal tissue during wound healing and regeneration. Bull. Tokyo Dent. Coll., 21(3):181-221, 1980.

Yamamura, T. Differentiation of pulpal cells and inductive influences of various matrices with reference to pulpal wound healing. J. Dent. Res., 64(Spec No):530-40, 1985.
Dirección para Correspondencia:

Prof. Dr. Luis Antonio Salazar

Departamento de Ciencias Básicas,

Facultad de Medicina

Universidad de La Frontera

Av. Francisco Salazar 01145

Casilla 54-D

Temuco

CHILE

Tel.: +56 45592895

Fax: +56 45592832

E-mail: Isalazar@ufro.cl

Recibido : 12-05-2011

Aceptado: 22-06-2011 